\title{
Influence of the dental implant number and load direction on stress distribution in a 3-unit implant-supported fixed dental prosthesis
}

\author{
Marcos Paulo Motta Silveira ${ }^{A-F}$, Larissa Mendes Campaner ${ }^{A-F}$, Marco Antonio Bottino ${ }^{A, C, E, F}$, Renato Sussumu Nishioka ${ }^{A, D-F}$, \\ Alexandre Luiz Souto Borges ${ }^{A, C, E, F}$, João Paulo Mendes Tribst ${ }^{A-F}$
}

Institute of Science and Technology, São Paulo State University (UNESP), São José dos Campos, Brazil

A - research concept and design; B - collection and/or assembly of data; C - data analysis and interpretation;

$D$ - writing the article; $E$ - critical revision of the article; $F$ - final approval of the article

Address for correspondence

João Paulo Mendes Tribst

E-mail: joao.tribs@@gmail.com

Funding sources

None declared

Conflict of interest

None declared

Received on November 2, 2020

Reviewed on November 12, 2020

Accepted on November 25, 2020

Published online on March 9, 2021

Cite as

Silveira MPM, Campaner LM, Bottino MA, Nishioka RS, Borges ALS, Tribst JPM. Influence of the dental implant number and load direction on stress distribution in a 3-unit implant-supported fixed dental prosthesis. Dent Med Probl. 2021;58(1):69-74. doi:10.17219/dmp/130847

DOI

$10.17219 / \mathrm{dmp} / 130847$

Copyright

(C) 2021 by Wroclaw Medical University

This is an article distributed under the terms of the

Creative Commons Attribution 3.0 Unported License (CC BY 3.0)

(https://creativecommons.org/licenses/by/3.0/).

\begin{abstract}
Background. The choice between 2 or 3 implants to support a 3-unit implant-supported fixed dental prosthesis (FDP) still generates doubt in clinical practice.

Objectives. The aim of this study was to evaluate stress distribution in 3-unit implant-supported FDPs according to the implant number and load direction.

Material and methods. A numerical simulation was performed to analyze stress and strain according to the implant number (2 or 3 ) and load direction (axial or oblique). A model of a jaw was created by means of the modeling software Rhinoceros, v. 5.0 SR8. External hexagon implants, micro-conical abutments and screws were also modeled. The final geometries were exported to the computer-aided engineering (CAE) software Ansys, v. 17.2, and all materials were considered homogeneous, isotropic and elastic. Different load directions were applied for each model $(300 \mathrm{~N})$ at the center of the prosthesis.
\end{abstract}

Results. The von Mises stress and strain values were obtained for the titanium structures and the bone, respectively. The implant number influenced the prosthesis biomechanics, with higher stress and strain concentrations when 2 implants were simulated. The oblique load also affected the mechanical response, showing higher stress and strain in comparison with the axial load, regardless of the implant number.

Conclusions. It was concluded that for a 3-unit implant-supported FDP, a greater number of implants associated with axial loads can result in a better mechanical response during chewing.

Key words: dental implants, finite element analysis, biomechanics, stress distribution, fixed dentures 


\section{Introduction}

Currently, implant-supported rehabilitation can be applied as predictable treatment. ${ }^{1}$ The literature affirms that implant-supported fixed dental prostheses (FDPs) increase the life quality of edentulous patients. ${ }^{2}$ However, some factors can affect the FDP longevity, e.g., the stress concentration, bone quality, or the dimensions and position of the implants. ${ }^{3}$

Considering the biomechanical response of an implantsupported FDP, the implant number is an important factor, since it may have an influence on how the masticatory load will be transmitted to the bone tissue. ${ }^{4}$ A large number of implants have a decisive effect on the mechanical response to prosthetic treatment. ${ }^{5}$ Placing an implant for each missing tooth is controversial and requires careful consideration in the most complex clinical situations. ${ }^{6}$

For a 3-unit implant-supported FDP, the choice between the use of 2 or 3 implants is related to the masticatory load and bone availability. ${ }^{7}$ When 3 implants are used, it is expected that less load will be transferred to the bone-implant interface. ${ }^{8}$ When more implants are used, the mechanical response from the central implant can be improved. ${ }^{9}$ However, it has been reported that the load direction also can modify the stress concentration in an implant-supported FDP. ${ }^{10}$ The biomechanical behavior of abutments, prosthetic screws and dental implants have not been investigated yet by comparing 2 or 3 implants with different load directions.

During chewing, the prosthetic components are constantly subjected to the combination of horizontal, vertical and oblique forces. ${ }^{11}$ The axial forces exerted on the implant are compressive in nature; however, horizontal or oblique resultant forces can increase lateral displacement, and consequently cause the formation of torsional forces and lever points, which - when excessive - can lead to failure in the prosthesis structure and at the bone-implant interface. ${ }^{12}$ Nonaxial loads in dental implant mechanical systems leave the prosthetic components at higher risk of failure due to fatigue. ${ }^{13}$

The number of implants depends on the type of rehabilitation that is to be performed. To improve the stability and support of an overdenture, 2-4 implants are recommended. ${ }^{14,15}$ In the literature, one can find studies which show implant survival data ranging from $95 \%$ to $100 \%$ for cases with 2 and 4 implants, and 81.8-96.1\% for 1 and 2 implants with immediate loading. ${ }^{16,17}$ A 3-unit FDP can resist a load of 500-600 N in the posterior region, regardless of the load condition. ${ }^{17}$ However, for a 3-unit implant-supported FDP, the literature is still scarce.

The finite element analysis (FEA) is an effective methodology for the in silico investigation of the mechanical response of FDPs. ${ }^{9-11}$ The finite element analysis can be used to analyze the mechanical behavior, the stress distribution and the direction of forces. When studying the longevity of prosthetic rehabilitation, biomechanics is of great importance in predicting failure in implants, since occlusal overload is a major cause of bone loss around implants, and consequently leads to the loss of prosthetic restorations and implants. ${ }^{18}$ Therefore, the aim of the present study was to investigate the biomechanical behavior and stress distribution of FDPs supported by 2 or 3 implants, submitted to different masticatory loads, using FEA. The null hypothesis was that there would be no difference in stress and strain according to the implant number and load direction.

\section{Material and methods}

The three-dimensional (3D) models consisted of a section of the maxilla and the following elements: external hexagon implants $(4.1 \mathrm{~mm}$ in diameter, $9 \mathrm{~mm}$ in length), mini-conical abutments $(4.0 \mathrm{~mm}$ in diameter, $1.5 \mathrm{~mm}$ in length), abutment screws, prosthetic screws (Titamax Ti; Neodent, Curitiba, Brazil), and a prosthesis. The models were created using the computer-aided design (CAD) software Rhinoceros, v. 5.0 SR8 (McNeel North America, Seattle, USA). The bone tissue was modeled as well; it contained the cortical bone of a thickness of $1.0 \mathrm{~mm}$ and the cancellous bone. The FDPs were created using a database from the Institute of Science and Technology at São Paulo State University (UNESP) in São José dos Campos, Brazil. They contained a maxillary first premolar, second premolar and first molar. ${ }^{18}$ The models were duplicated in 2 groups: the $1^{\text {st }}$ group received 2 implants at the ends of the prosthesis; and the $2^{\text {nd }}$ group received 3 implants, 1 for each tooth, according to Fig. 1 . All volumetric solids were assumed to have the same number of faces connected to each other.

All the models were exported to the computeraided engineering (CAE) software Ansys, v. 17.2 (ANSYS Inc., Houston, USA) in the STEP format, and the tetrahedral elements formed the mesh. The properties of each material are summarized in Table 1; the models were considered homogeneous, isotropic and elastic.

Table 1. Mechanical properties of the materials used in the finite element analysis (FEA)

\begin{tabular}{|l|c|c|}
\multicolumn{1}{|c|}{ Structure } & $\begin{array}{c}\text { Elastic modulus } \\
{[\mathrm{GPa}]}\end{array}$ & Poisson's ratio \\
\hline Titanium & 110 & 0.3 \\
\hline Zirconia & 220 & 0.3 \\
Cortical bone & 14 & 0.3 \\
\hline Trabecular bone & 1.4 & 0.3 \\
\hline
\end{tabular}



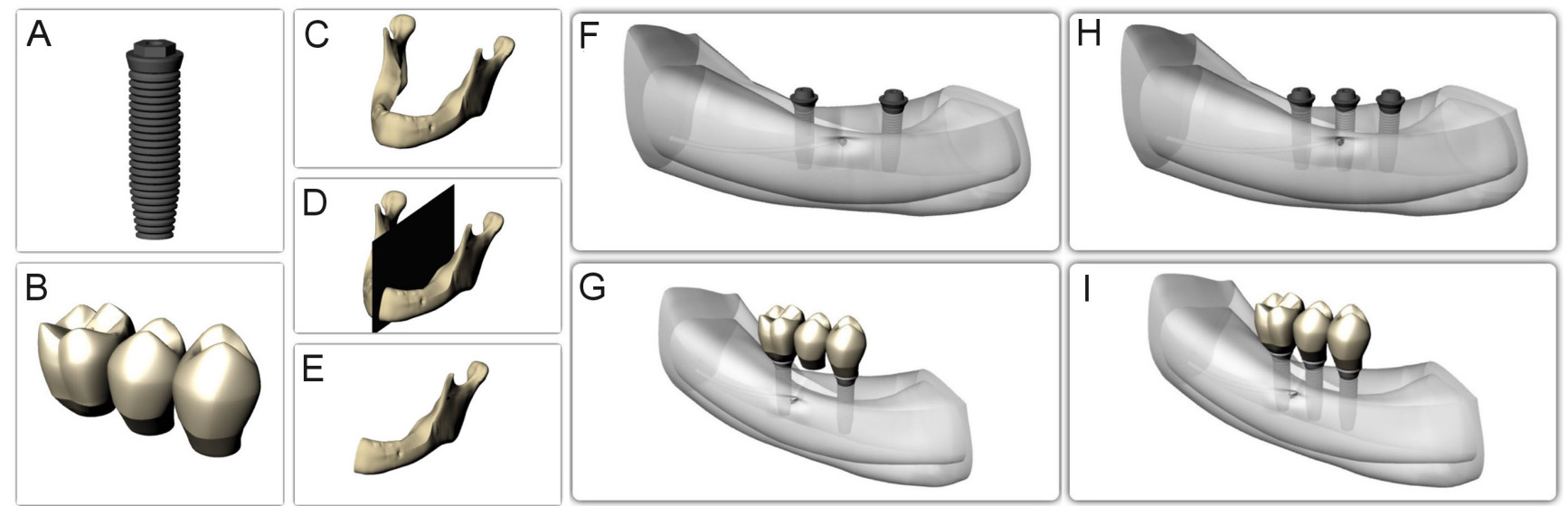

Fig. 1. Three-dimensional (3D) modeling for the numerical simulation

A - external hexagon implant model; B - posterior 3-unit fixed dental prosthesis (FDP); C - edentulous jaw; D - cutting plane for the section model; E - hemi-jaw model; F - 2-implant model; G - 2-implant model with the FDP; H - 3-implant model; I - 3-implant model with the FDP.

The models were restricted in all directions on the cortical bone surface. The zones of non-linear contact were defined in 4 critical interfaces: implant-bone; implant -abutment; implant-screw; and abutment-screw. The contact analysis defined the load transfer and deformation between different components. The friction coefficient was defined as 0.3 for all titanium-titanium interfaces, ${ }^{19} 0.65$ for the cortical bone-implant interface ${ }^{20}$ and 0.77 for the cancellous bone-implant interface. ${ }^{21}$

For the masticatory force simulation, a load of $300 \mathrm{~N}^{22,23}$ was applied to the center of the prosthesis in 2 different directions: axial to the central implant; and obliquely at $45^{\circ}$ in relation to the long axis of the central implant.

The results were required as the von Mises stress criteria for ductile solids. For the peri-implant tissue, the required result was expressed as the microstrain value based on a previous study, which correlated this criterion with bone reabsorption. ${ }^{24}$ Results that presented a difference in stress peaks between the same regions which was higher than $10 \%$ were defined as significant based on the mesh convergence test. ${ }^{21-23}$

\section{Results}

Regarding the implant number and load direction, the strain values in the bone were plotted in colorimetric graphs (Fig. 2). It could be observed that the larger the number of implants to support the FDP was, the less strain was concentrated in the bone tissue (Fig. 2A,2C and Fig. 2B,2D). One can notice that strain was homogeneously concentrated in the cervical region between all the implants. The oblique load increased the strain magnitude, regardless of the implant number (Fig. 2B,2D).

With regard to von Mises stress in the dental implants, it could be observed that the external hexagon region was the most involved in the stress concentration, regardless of the model (Fig. 3). However, using the central implant

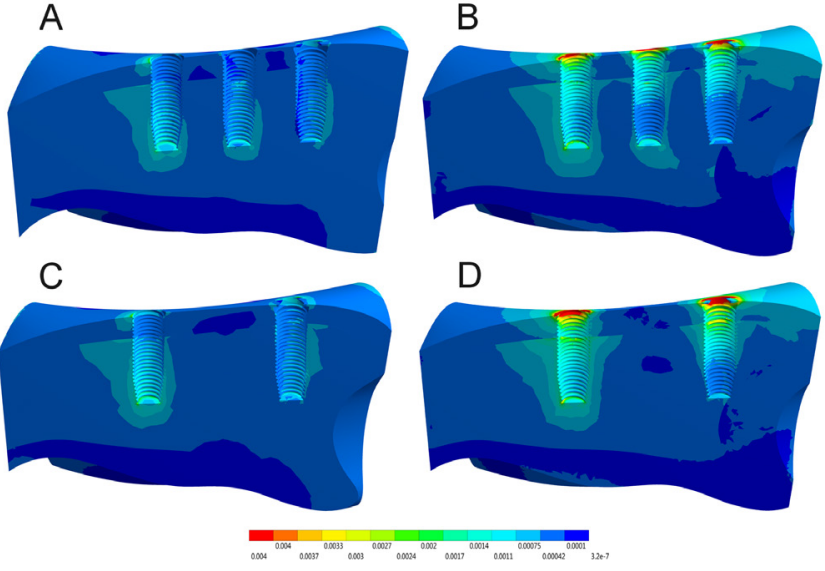

Fig. 2. Bone microstrain maps for 3 implants with the axial load (A), 3 implants with the oblique load (B), 2 implants with the axial load (C), and 2 implants with the oblique load (D)
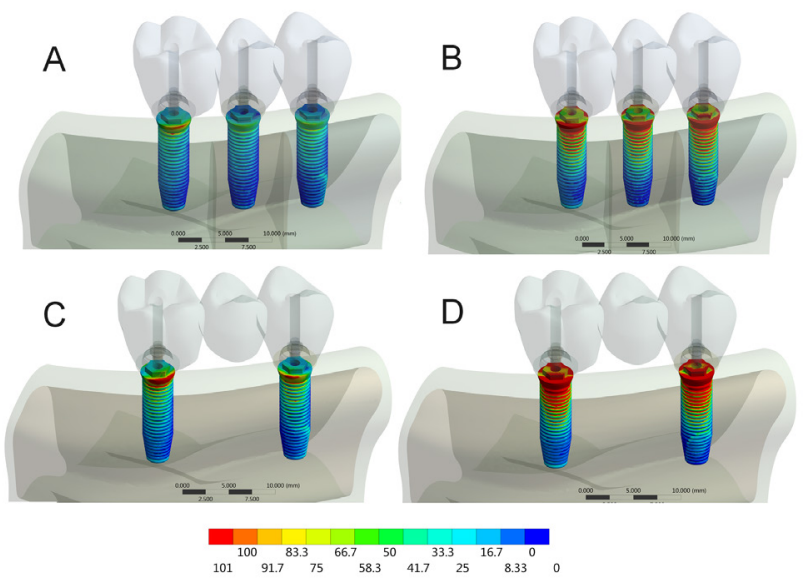

Fig. 3. von Mises stress maps in the implants for 3 implants with the axial load (A), 3 implants with the oblique load (B), 2 implants with the axial load (C), and 2 implants with the oblique load (D)

may reduce the stress magnitude, even for the oblique load. The same behavior can be noted for the microconical abutment (Fig. 4) and the prosthetic screw (Fig. 5). 
The microstrain peaks and stress peaks were recorded for each tooth and are summarized in Table 2.

According to Wolff's law, ${ }^{24}$ strain values below $50 \mathrm{~mm} / \mathrm{mm}$ are able to promote bone remodeling due to disuse, and values above $3,000 \mathrm{~mm} / \mathrm{mm}$ are able to promote bone remodeling by microdamage. There was no simulated model which could prevent or promote bone remodeling; however, the use of 3 implants with the axial load may reduce the risk of bone remodeling.
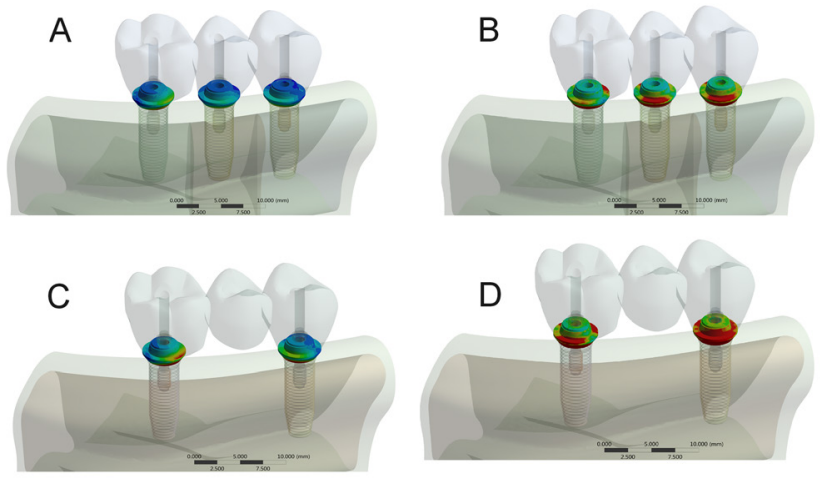

Fig. 4. von Mises stress maps in the micro-conical abutment for 3 implants with the axial load (A), 3 implants with the oblique load (B), 2 implants with the axial load (C), and 2 implants with the oblique load (D)
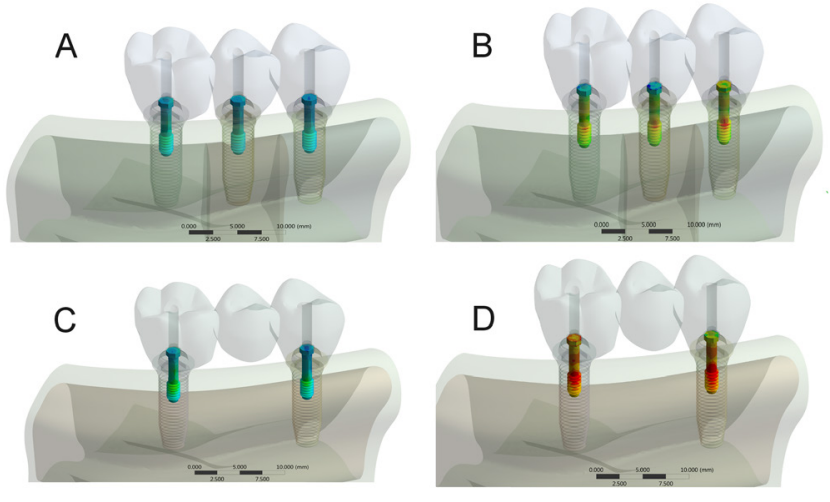

Fig. 5. von Mises stress maps in the prosthetic screw for 3 implants with the axial load (A), 3 implants with the oblique load (B), 2 implants with the axial load (C), and 2 implants with the oblique load (D)

\section{Discussion}

This study evaluated the influence of the implant number and load direction in an implant-supported FDP on the bone strain and von Mises stress. The results showed that there was a direct relationship between the implant number and the calculated strain. It was also possible to observe that the axial load promoted less stress and strain. Based on the results, the null hypothesis was rejected, because there was an influence of the load and implant number on the mechanical response.

A previous study evaluated the influence of the number of implants on the biomechanical behavior of overdentures, using the FEA method. ${ }^{25}$ In overdentures retained by 2 implants, the level of stress in the periimplant bone and on the abutment was higher in comparison with a situation when 3 implants were used. According to the authors, the stress generated around the central implant was reduced, which was beneficial for the peri-implant bone. ${ }^{25}$ The present study corroborates this statement, since the use of 3 implants reduced the risk of bone remodeling and damage to the abutments, screws and implants.

Another investigation evaluated the effect of the diameter, length and number of implants on stress distribution in the peri-implant bone of a 3-unit implant-supported FDP. ${ }^{26}$ The authors concluded that the use of only 2 implants of a diameter of $4.1 \mathrm{~mm}$ was sufficient to retain partial prostheses without causing damage to the cortical bone. In addition, the researchers reported that when using the central implant in the case of the prostheses supported by 3 implants, the magnitude of the generated stress could be reduced, which did not occur in the case of the prostheses supported by only 2 implants. ${ }^{26}$ The present study corroborates those observations, since the use of the central implant in the case of the prosthesis supported by 3 implants reduced the magnitude of stress, even for the oblique load. In addition, the present study complements this previous report, showing that the micro-conical abutment and also the prosthetic screw may present a reduced stress concentration when $3 \mathrm{im}$ plants are used.

Table 2. Results in terms of bone microstrain $[\mu \varepsilon]$ and stress [MPa] peak values according to the load direction and implant number

\begin{tabular}{|c|c|c|c|c|c|c|c|c|c|c|c|c|}
\hline \multirow{3}{*}{ Region } & \multicolumn{6}{|c|}{ Axial load } & \multicolumn{6}{|c|}{ Oblique load } \\
\hline & \multicolumn{3}{|c|}{2 implants } & \multicolumn{3}{|c|}{3 implants } & \multicolumn{3}{|c|}{2 implants } & \multicolumn{3}{|c|}{3 implants } \\
\hline & molar & \begin{tabular}{|c|} 
first \\
premolar
\end{tabular} & $\begin{array}{l}\text { second } \\
\text { premolar }\end{array}$ & molar & \begin{tabular}{|c|} 
first \\
premolar
\end{tabular} & $\begin{array}{l}\text { second } \\
\text { premolar }\end{array}$ & molar & \begin{tabular}{|c|} 
first \\
premolar
\end{tabular} & \begin{tabular}{|l|} 
second \\
premolar
\end{tabular} & molar & \begin{tabular}{|c|} 
first \\
premolar
\end{tabular} & \begin{tabular}{|l|} 
second \\
premolar
\end{tabular} \\
\hline $\begin{array}{l}\text { Bone } \\
{[\mu \varepsilon]}\end{array}$ & 2,202 & 215 & 1,954 & 1,916 & 641 & 544 & 4,189 & 278 & 3,967 & 2,991 & 2,789 & 2,836 \\
\hline $\begin{array}{l}\text { Implant } \\
\text { [MPa] }\end{array}$ & 21.5 & - & 21.3 & 18.3 & 11.8 & 4.9 & 66.6 & - & 61.7 & 30.3 & 30.4 & 28.8 \\
\hline $\begin{array}{l}\text { Micro-conical abutment } \\
\text { [MPa] }\end{array}$ & 31.7 & - & 24.8 & 25.5 & 15.5 & 14.7 & 40.2 & - & 44.3 & 37.8 & 36.8 & 38.1 \\
\hline $\begin{array}{l}\text { Prosthetic screw } \\
{[\mathrm{MPa}]}\end{array}$ & 24.3 & - & 24.7 & 16.7 & 15.4 & 15.3 & 64.5 & - & 55.9 & 39.6 & 44.3 & 45.1 \\
\hline
\end{tabular}


The literature shows that the larger the number of implants is, the less stress is generated in the peri-implant bone. ${ }^{27,28}$ In the present study, the results suggest that the use of 3 implants may help reduce the possible strain in the cortical bone, thus reducing the risk of causing bone damage and bone remodeling; however, axial loads should be planned.

This study simulated a 300-newton load for the test, ${ }^{29}$ with 2 different directions - oblique at $45^{\circ}$ in relation to the long axis of the implants and axial. In previous studies, one can find different load magnitude used, yet in similar directions. ${ }^{30,31}$

Araki et al. simulated an occlusal load with different directions. ${ }^{29}$ However, their results were similar, since it was possible to verify that the highest stress concentration was located in the cervical area of the cortical bone. In this way, the present study corroborates those results, stating that the cervical region is the most affected bone region. ${ }^{32}$

The present study also showed that the use of the central implant decreased the stress concentration, even for the oblique load. The analysis of previous studies shows that the implant design and different lengths also can affect stress distribution. ${ }^{10,29-32}$ This must be considered relevant in the surgical planning, focusing on reducing the stress concentration and the cervical bone resorption.

Another research, a clinical study performed on unitary implants, reported the development of some problems before the catastrophic fracture of an implant, e.g., the loosening of the screw, peri-implantitis and the peri-implant bone resorption. ${ }^{33}$ Problems such as the peri-implant bone resorption can be noticed in unit rehabilitation, with crowns of an inadequate height or unsuitable for the patient's occlusal function. Due to the dissipation of axial and oblique loads, the larger the number of implants in rehabilitation, the lower the stress concentration that can generate bone resorption around the implants. In this way, the present study suggests that the load direction should be possibly the most axial to reduce the failure risk.

Over the last decades, the FEA method has become an increasingly useful tool to predict the effects of the generated stress on implants and the peri-implant bone. ${ }^{34,35}$ This method allows the analytical assessment of load distribution on the implant structure, controlling the possible microstrain as well as identifying the load direction and understanding the impact of the implant number. ${ }^{36}$

In implantology, FEA has been widely used to study the stress patterns of the implant components and also in the peri-implant bone. The success of FEA depends on precision in the simulation of the implant surface geometry and structure, according to the characteristics of the implant material, the load and support conditions as well as the biomechanical and interface conditions. Since it was an in silico study, clinical conditions might have not been fully replicated. ${ }^{37,38}$ The stress analysis is normally performed under static load, and the mechanical properties of the materials are defined as isotropic and linearly elastic, although this is not the case in reality. ${ }^{39}$ Thus, this analysis allows predicting biomechanical behavior in different situations; still, the results must also be considered qualitatively.

It is important to note that the absence of a microgap in the present model should be considered as a limitation of this study, since it is reported to be a factor that could affect the bone response as well as the implant structure, types of surfaces, shapes, and materials used in the prosthetic system. ${ }^{40}$

In this study, it can be noticed that the use of a greater number of implants reduced the stress concentration under oblique load. However, another way to achieve better load distribution could be the manufacturing of prosthetic crowns that would conform with the patient's occlusal reality, of sizes and shapes adequate to the chewing function. Digital protocol and chairside can assist in achieving the optimal implant placement and crown design.

\section{Conclusions}

Considering the limitations of this study, it can be concluded that for a 3-unit implant-supported FDP, a greater number of implants associated with axial loads can result in a better mechanical response during chewing.

\section{ORCID iDs}

Marcos Paulo Motta Silveira (1) https://orcid.org/0000-0001-9061-8565 Larissa Mendes Campaner (1) https://orcid.org/0000-0002-3262-2379 Marco Antonio Bottino (1) https://orcid.org/0000-0003-0077-3161 Renato Sussumu Nishioka (1) https://orcid.org/0000-0002-1458-601X Alexandre Luiz Souto Borges (10 https://orcid.org/0000-0002-5707-7565 João Paulo Mendes Tribst [1] https://orcid.org/0000-0002-5412-3546

\section{References}

1. Bianco E. Factors influencing immediate maxillary dental implant placement and bone resorption: A review of the literature and an outlook on the clinical possibilities. Dent Med Probl. 2016;53(3):408-412. doi:10.17219/dmp/63185

2. Papaspyridakos P, Chen CJ, Singh M, Weber HP, Gallucci GO. Success criteria in implant dentistry: A systematic review. J Dent Res. 2012;91(3):242-248. doi:10.1177/0022034511431252

3. Jafarian M, Mirhashemi FS, Emadi N. Finite element analysis of stress distribution around a dental implant with different amounts of bone loss: An in vitro study. Dent Med Probl. 2019;56(1):27-32. doi:10.17219/dmp/102710

4. Lee JY, Kim HY, Shin SW, Bryant SR. Number of implants for mandibular implant overdentures: A systematic review. J Adv Prosthodont. 2012;4(4):204-209. doi:10.4047/jap.2012.4.4.204

5. Sahin S, Cehreli MC, Yalçin E. The influence of functional forces on the biomechanics of implant-supported prostheses - a review. J Dent. 2002;30(7-8):271-282. doi:10.1016/s0300-5712(02)00065-9

6. Ravald N, Dahlgren S, Teiwik A, Gröndahl K. Long-term evaluation of Astra Tech and Brånemark implants in patients treated with full-arch bridges. Results after 12-15 years. Clin Oral Implants Res. 2013;24(10):1144-1151. doi:10.1111/j.1600-0501.2012.02524.x

7. Lee Jl, Lee Y, Kim YL, Cho HW. Effect of implant number and distribution on load transfer in implant-supported partial fixed dental prostheses for the anterior maxilla: A photoelastic stress analysis study. J Prosthet Dent. 2016;115(2):161-169. doi:10.1016/j.prosdent.2015.08.021 
8. Kunavisarut C, Lang LA, Stoner BR, Felton DA. Finite element analysis on dental implant-supported prostheses without passive fit. J Prosthodont. 2002;11(1):30-40. doi:10.1111/j.1532-849x.2002.00030.x

9. Topkaya T, Solmaz MY. The effect of implant number and position on the stress behavior of mandibular implant retained overdentures: A three-dimensional finite element analysis. J Biomech. 2015;48(10):2102-2109. doi:10.1016/j.jbiomech.2015.03.006

10. Brune A, Stiesch M, Eisenburger M, Greuling A. The effect of different occlusal contact situations on peri-implant bone stress - a contact finite element analysis of indirect axial loading. Mater Sci Eng C Mater Biol Appl. 2019;99:367-373. doi:10.1016/j.msec.2019.01.104

11. Tepper G, Haas R, Zechner W, Krach W, Watzek G. Three-dimensional finite element analysis of implant stability in the atrophic posterior maxilla: A mathematical study of the sinus floor augmentation. Clin Oral Implants Res. 2002;13(6):657-665. doi:10.1034/j.1600-0501.2002.130613.x

12. Watanabe F, Hata Y, Komatsu S, Ramos TC, Fukuda H. Finite element analysis of the influence of implant inclination, loading position, and load direction on stress distribution. Odontology. 2003;91(1):31-36. doi:10.1007/s10266-003-0029-7

13. de Melo Filho AB, Tribst JPM, de Carvalho Ramos N, et al. Failure probability, stress distribution and fracture analysis of experimental screw for micro conical abutment. Braz Dent J. 2019;30(2):157-163. doi:10.1590/0103-6440201902401

14. Thomason JM, Kelly SAM, Bendkowski A, Ellis JS. Two implant retained overdentures - a review of the literature supporting the McGill and York consensus statements. J Dent. 2012;40(1):22-34. doi:10.1016/j.jdent.2011.08.017

15. Thomason JM, Feine J, Exley $C$, et al. Mandibular two implantsupported overdentures as the first choice standard of care for edentulous patients - the York Consensus Statement. Br Dent J. 2009;207(4):185-186. doi:10.1038/sj.bdj.2009.728

16. Kronstrom M, Davis B, Loney R, Gerrow J, Hollender L. A prospective randomized study on the immediate loading of mandibular overdentures supported by one or two implants: A 12-month follow-up report. Int J Oral Maxillofac Implants. 2010;25(1):181-188. PMID:20209200

17. Alkharrat $A R, S c h m i t t e r M$, Rues $S$, Rammelsberg P. Fracture behavior of all-ceramic, implant-supported, and tooth-implant-supported fixed dental prostheses. Clin Oral Investig. 2018;22(4):1663-1673. doi:10.1007/s00784-017-2233-9

18. Tribst JPM, Rodrigues VA, Dal Piva AMdO, Borges ALS, Nishioka RS. The importance of correct implants positioning and masticatory load direction on a fixed prosthesis. J Clin Exp Dent. 2018;10(1):e81-e87. doi:10.4317/jced.54489

19. Alkan I, Sertgöz A, Ekici B. Influence of occlusal forces on stress distribution in preloaded dental implant screws. J Prosthet Dent. 2004;91(4):319-325. doi:10.1016/j.prosdent.2004.01.016

20. Yu HY, Cai ZB, Zhou ZR, Zhu MH. Fretting behavior of cortical bone against titanium and its alloy. Wear. 2005;259(7-12):910-918. doi:10.1016/j.wear.2005.01.037

21. Tribst JPM, Dal Piva AMdO, Borges ALS, Nishioka RS, Bottino MA, Rodrigues VA. Effect of framework type on the biomechanical behavior of provisional crowns: Strain gauge and finite element analyses. Int J Periodontics Restorative Dent. 2020;40(1):e9-e18. doi:10.11607/prd.4061

22. Tribst JPM, Dal Piva AMdO, Lo Giudice R, et al. The influence of custommilled framework design for an implant-supported full-arch fixed dental prosthesis: 3D-FEA study. Int J Environ Res Public Health. 2020;17(11):4040. doi:10.3390/ijerph17114040

23. Tribst JPM, Dal Piva AMdO, Borges ALS, Bottino MA. Influence of Socket-shield technique on the biomechanical response of dental implant: Three-dimensional finite element analysis. Comput Methods Biomech Biomed Engin. 2020;23(6):224-231. doi:10.1080/10255842.2019.1710833

24. Frost HM. Wolff's Law and bone's structural adaptations to mechanical usage: An overview for clinicians. Angle Orthod. 1994;64(3):175-188. doi:10.1043/0003-3219(1994)064<0175:WLABSA >2.0.CO;2

25. Liu J, Pan S, Dong J, Mo Z, Fan Y, Feng H. Influence of implant number on the biomechanical behaviour of mandibular implant-retained/ supported overdentures: A three-dimensional finite element analysis. J Dent. 2013;41(3):241-249. doi:10.1016/j.jdent.2012.11.008
26. Iplikçioğlu H, Akça K. Comparative evaluation of the effect of diameter, length and number of implants supporting three-unit fixed partial prostheses on stress distribution in the bone. J Dent. 2002;30(1):41-46. doi:10.1016/s0300-5712(01)00057-4

27. Takahashi T, Shimamura I, Sakurai K. Influence of number and inclination angle of implants on stress distribution in mandibular cortical bone with All-on-4 Concept. J Prosthodont Res. 2010;54(4):179-184. doi:10.1016/j.jpor.2010.04.004

28. Tribst JPM, Dal Piva AMdO, Borges ALS, Rodrigues VA, Bottino MA, Kleverlaan CJ. Does the prosthesis weight matter? 3D finite element analysis of a fixed implant-supported prosthesis at different weights and implant numbers. J Adv Prosthodont. 2020;12(2):67-74. doi:10.4047/jap.2020.12.2.67

29. Araki $\mathrm{H}$, Nakano $\mathrm{T}$, Ono $\mathrm{S}$, Yatani $\mathrm{H}$. Three-dimensional finite element analysis of extra short implants focusing on implant designs and materials. Int J Implant Dent. 2020;6(1):5. doi:10.1186/s40729-019-0202-6

30. Geramizadeh M, Katoozian H, Amid R, Kadkhodazadeh M. Comparison of finite element results with photoelastic stress analysis around dental implants with different threads. Dent Med Probl. 2018;55(1):17-22. doi:10.17219/dmp/85077

31. Tribst JPM, Dal Piva AMdO, Borges ALS, Bottino MA. Effect of implant number and height on the biomechanics of full arch prosthesis. Braz J Oral Sci. 2018;17:e18222. doi:10.20396/bjos.v17i0.8653837

32. Tribst JPM, Dal Piva AMdO, Borges ALS, Anami LC, Kleverlaan CJ, Bottino MA. Survival probability, Weibull characteristics, stress distribution, and fractographic analysis of polymer-infiltrated ceramic network restorations cemented on a chairside titanium base: An in vitro and in silico study. Materials (Basel). 2020;13(8):1879. doi:10.3390/ma13081879

33. Yu HC, Kim YK. Fractures of implant fixtures: A retrospective clinical study. Maxillofac Plast Reconstr Surg. 2020;42(1):13. doi:10.1186/ s40902-020-00258-3

34. Çaglar A, Bal BT, Karakoca S, Aydın C, Yılmaz H, Sarısoy S. Threedimensional finite element analysis of titanium and yttriumstabilized zirconium dioxide abutments and implants. Int J Oral Maxillofac Implants. 2011;26(5):961-969. PMID:22010077

35. Oliveros-López LG, Castillo-de-Oyagüe R, Serrera-Figallo MA, et al. Bone loss in bruxist patients wearing dental implant prostheses: A finite element analysis. Metals. 2020;10(9):1132. doi:10.3390/met10091132

36. Villefort RF, Tribst JPM, Dal Piva AMdO, et al. Stress distribution on different bar materials in implant-retained palatal obturator. PLoS One. 2020;15(10):e0241589. doi:10.1371/journal.pone.0241589

37. Pammer D. Evaluation of postoperative dental implant primary stability using 3D finite element analysis. Comput Methods Biomech Biomed Engin. 2019;22(3):280-287. doi:10.1080/10255842.2018.1552682

38. Szymańska J, Szpak P. Marginal bone loss around dental implants with conical and hexagonal implant-abutment interface: A literature review. Dent Med Probl. 2017;54(3):279-284. doi:10.17219/dmp/74143

39. Reddy MS, Sundram R, Eid Abdemagyd HA. Application of finite element model in implant dentistry: A systematic review. J Pharm Bioallied Sci. 2019;11(Suppl 2):S85-S91. doi:10.4103/JPBS.JPBS_296_18

40. Łukaszewska-Kuska M, Krawczyk P, Martyla A, Hędzelek W, DorockaBobkowska B. Effects of a hydroxyapatite coating on the stability of endosseous implants in rabbit tibiae. Dent Med Probl. 2019;56(2):123-129. doi:10.17219/dmp/103851 